\title{
Trends over time in prescribing by English primary care nurses: a secondary analysis of a national prescription database
}

\author{
Vari M Drennan*, Robert L Grant and Ruth Harris
}

\begin{abstract}
Background: A growing number of countries legislate for nurses to have medication prescribing authority although it is a contested issue. The UK is one of these countries, giving authority to nurses with additional qualifications since 1992 and incrementally widened the scope of nurse prescribing, most recently in 2006. The policy intention for primary care was to improve efficiency in service delivery through flexibility between medical and nursing roles. The extent to which this has occurred is uncertain. This study investigated nurses prescribing activities, over time, in English primary care settings.
\end{abstract}

Methods: A secondary data analysis of a national primary care prescription database 2006-2010 and National Health Service workforce database 2010 was undertaken.

Results: The numbers of nurses issuing more than one prescription annually in primary care rose from 13,391 in 2006 to 15,841 in 2010. This represented forty three percent of those with prescribing qualifications and authorisation from their employers. The number of items prescribed by nurses rose from $1.1 \%$ to $1.5 \%$ of total items prescribed in primary care. The greatest volume of items prescribed by independent nurse prescribers was in the category of penicillins, followed by dressings. However, the category where independent nurse prescribers contributed the largest proportion of all primary care prescriptions was emergency contraception (9.1\%). In contrast, community practitioner nurse prescribers' greatest volume and contribution was in the category of gel and colloid dressings (27\%), medicated stockings (14.5\%) and incontinence appliances (4.2\%). There were slightly higher rates of nurse prescribing in areas with higher levels of socio-economic deprivation and fewer physicians per capita, but the correlations were weak and warrant further investigation.

Conclusions: The percentage of prescriptions written by nurses in primary care in England is very small in comparison to physicians. Our findings suggest that nurse prescribing is used where it is seen to have relative advantage by all stakeholders, in particular when it supports efficiency in nursing practice and also health promotion activities by nurses in general practice. It is in these areas that there appears to be flexibility in the prescribing role between nurses and general practitioners.

Keywords: Non-medical prescribing, Nurse prescribing, Nurse roles, Primary care, Secondary analysis, Medication management

\footnotetext{
* Correspondence: v.drennan@sgul.kingston.ac.uk

Faculty of Health, Social Care \& Education, Kingston University \& St George's, University of London, London, UK
}

\section{Ciomed Central}

(c) 2014 Drennan et al.; licensee BioMed Central Ltd. This is an Open Access article distributed under the terms of the Creative Commons Attribution License (http://creativecommons.org/licenses/by/2.0), which permits unrestricted use, distribution, and reproduction in any medium, provided the original work is properly credited. 


\section{Background}

Access to safe and affordable medicines is one element of all countries' strategies for ensuring public health [1]. Some countries have legislated for nurses to have authority to prescribe medicines, as part of national strategies for improving safety and efficiency in access to prescribed medicines, particularly in primary care settings and more countries are considering doing so [2]. The introduction of prescribing by nurses in most countries has been in response to either issues of shortages of physicians in rural and remote areas [3-8] or in response to perceived inefficiencies in primary health care delivery $[9,10]$. There is variation between countries as to the classes of medicines that nurses are authorised to prescribe and the qualifications of nurses with that authority. For example all registered nurses in South Africa can prescribe, but only for some classes of medicines, while in Australia only those with nurse practitioner qualifications can prescribe from a state- or territory-approved medicine list within their scope of practice [1].

The extent to which a health care innovation becomes integrated into usual practice depends on the interaction between features of the innovation, the adopter(s), and the context [11]. Government commissioned evaluations from Northern European countries at single points in time report the innovation of nurse prescribing as well received by patients, clinically appropriate and safe $[12,13]$. At a theoretical level the context for nurse prescribing is one of the shifting and contested boundaries of jurisdiction between professional groups in health care [14]. Prescribing by nurses' remains a disputed innovation $[15,16]$ including by some medical professionals [17-20]. At the same time, although nursing professional organisations in many countries have actively sought prescriptive authority [21-24], some nurses have expressed concerns regarding appropriate training, support and remuneration for this role [25-28] and ambivalence to a more medically orientated role [29-31]. The contextual influences are demonstrated by the variation in rates of self-reported levels of use of prescribing authority by nurses. Surveys of nurse practitioners in the United States of America report over 90\% regularly using their authority to prescribe $[32,33]$, in comparison to a survey of Australian nurse practitioners with endorsement to prescribe, which found that $41 \%$ did not prescribe [34]. The adoption of health care innovation also changes over time. Studies of nurse prescribing to date have drawn prescribing evidence at single points in time or from aggregated data $[12,13,35,36]$, often in relation to programmes targeted at specific patient populations [5,37] or particular types of medicines such as analgesics or antidepressants [38,39].

This study investigated the extent of the use of prescribing authority by primary care nurses over five years in the context of English government health policies which supported greater flexibility in health professional roles to improve access and efficiency in primary care $[40,41]$. An incremental history of legislation and implementation in England [42-47] culminated in 2006 with registered nurses with additional independent prescribing qualifications being authorised to prescribe any licensed medicine, including some Controlled Drugs, for any medical condition within their clinical competence and scope of practice (see Table 1).

This incremental history has also resulted in two types of qualification for prescribing by nurses [48]:

- An independent prescribing qualification for nurses (INP) to prescribe, within their scope of practice, any licensed medication including some controlled drugs [48]. Registered nurses, with more than three years clinical practice, can with their employers support undertake a Nursing and Midwifery Council (NMC) approved, theoretical (minimum of 26 days) and supervised practise (12 days) course for independent prescribing. The practice element includes supervision and assessment by a designated medical practitioner [49]. The course is at degree level or may be part of masters programmes.

- A community practitioner nurse prescriber (CPNP) qualification to prescribe from a limited formulary [48]. Registered nurses working or intending to work in primary care or community can undertake a NMC approved course as part of a degree level specialist community qualification or as a standalone course [49]. This nurse formulary is a nationally agreed limited list including items such as emollients, laxatives, anti-fungal preparations, some analgesics (e.g. paracetamol, aspirin, ibuprofen), nicotine replacement products, parasiticidal preparations, and wound management products, catheters and catheter management preparations [50].

A previous systematic review [51] and subsequent updating found no United Kingdom (UK) studies that reported from objective prescribing data by nurses in primary care (although as the review noted some studies may have included data from primary care but it was not possible to separate from that in hospital settings). This study addressed the following research questions:

- What percentage of nurses, with authorisation to prescribe in primary care, used their prescribing authority and has this changed over the first five years of independent nurse prescribing? 
Table 1 Legislative authority and NHS mechanisms for nurses to prescribe medicines in the UK from 1992

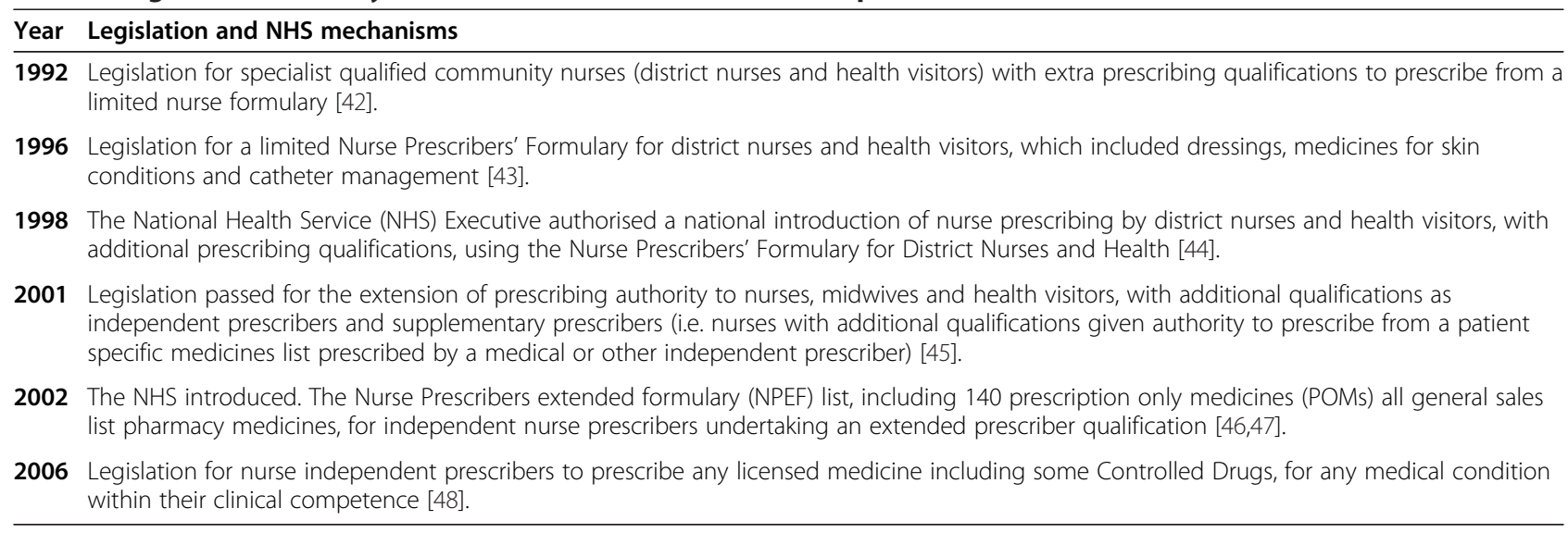

- What types of medications are prescribed in the greatest volume by nurse prescribers with authorisation to prescribe in primary care?

- For what types of medications do nurse prescribers with authorisation contribute the greatest proportion of primary care prescriptions, and does this suggest any flexibility between the roles of physicians and nurses?

- Are there primary care contextual circumstances in which nurses are more actively prescribing medicines?

\section{Methods}

The study design was a secondary data analysis of the administrative records of National Health Service (NHS) primary care prescriptions and contextual primary care environment and workforce data in England available in the public domain.

\section{Setting}

The NHS is a tax funded health service which provides for universal registration as a patient with primary care general practitioners (GPs) [52]. GPs are known as family physicians in some countries. GPs employ practice nurses to work in their practices or surgeries. Their patients are also provided services by district nurses (known as home visiting nurses in some countries) and health visitors (known as public health nurses in some countries). These nurses were employed by community health services in local area NHS organisations, which were called Primary Care Trusts (PCTs) at the time of the study. In 2010, there were 154 PCTs in England with a median patient population of 298,391 (quartiles 227,944 and 431,018) registered with GPs [53]. Within England there are two prescribing qualifications $[47,48]$ of interest in this study:
- An independent prescribing qualification for nurses (INP) to prescribe, within their scope of practice, any licensed medication including some controlled drugs.

- A community practitioner nurse prescriber (CPNP) qualification to prescribe from a limited formulary.

\section{Sample}

Every NHS prescription issued and dispensed for a general practice patient is entered onto the administrative database of the NHS Business Service Authority called ePACT (electronic Prescribing Analysis and Cost). The database both identifies the prescriber by a unique identifying code and also links the prescription to the GP with whom the patient is registered. Nurse prescribers have to be authorised by their employer to be registered and receive a unique identifying number with ePACT. The ePACT database is comprehensive in managing NHS primary care prescribing and dispensing costs across England.

\section{Data collection}

Data on all prescriptions (irrespective of type of prescriber) were obtained from ePACT under the terms of the Freedom of Information Act 2000 [54] from October 2006 to September 2010. The ePACT data obtained provided the following variables: the number of items prescribed by the categories in the British National Formulary (BNF) [53], the location by the PCT, the type of prescriber (GP or nurse), and for nurses their qualification (independent or community prescriber) and employer (PCT or a GP). Data on the primary care context were obtained from the NHS Information Centre [50] for each PCT area. This included the following data: percentage of GPs per 1000 capita, percentage of single handed (i.e. a solo medical practitioner) general practices, percentage of general practice patients aged under 15 , and percentage of general practice patients aged over 
65. In addition a measure of socio-economic deprivation, the Index of Multiple Deprivation [55], was obtained for each PCT [56].

We also obtained the number of nurses GPs and nurses registered with ePACT at 1 April each year from 2006 to 2010 inclusive.

\section{Ethical considerations}

Ethical approval was not required for this secondary analysis of organisation-level data in the public domain.

\section{Data analysis}

Data were analysed descriptively using Stata software, version 11 [57]. When calculating nurse prescriptions as a proportion of all primary care, categories of drugs and devices were included only if more than 10,000 items were prescribed in total over the five years. As the data represents every primary care prescription in England during the time period, the only role of inferential statistics would be in extrapolating to the future or comparing specific organisations, which was not our aim.

There were a small number of ePACT records where the profession or the location was unknown, which were only included in overall national statistics. For this analysis, we omitted those prescribers with only one prescription in a year to avoid coding errors. A limitation of ePACT data in the public domain is that individual patients and prescribers are not identified. Consequently prescriptions made for, or by, the same person cannot be linked.

\section{Results}

Between 2006-2010 the number of nurses registered by their employers to prescribe with ePACT rose by $18 \%$ from 30,753 to 36,281 (Figure 1). The greatest increase was those with independent nurse prescribing qualifications (INPs) from 5014 to 12975 while the Community

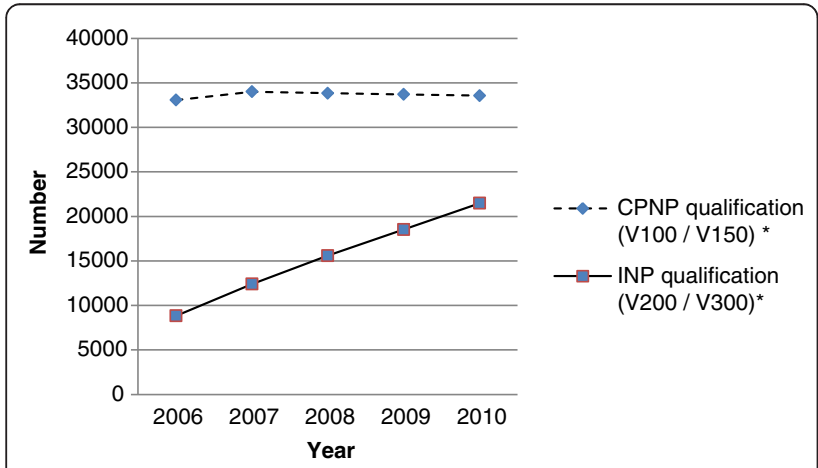

Figure 1 Trends in numbers of nurses with prescribing qualifications (UK) 2006-2010*. *Data source: Nursing and Midwifery Council [40] and personal communication from N. Rossi, NMC communications officer to R.L. Grant. 2011.
Practitioner Nurse Prescribers (CPNPs), who use a limited formulary, decreased by 2437 .

While the numbers of nurses actively prescribing, as recorded on ePACT by 2 or more prescriptions in a year, rose in the time period by $18 \%$ from 13,391 to 15,841 , this remained at $43 \%$ of all those nurses registered with ePACT to prescribe. A greater percentage of those with independent nurse prescribing qualifications registered with ePACT were actively prescribing in the time period (from $65 \%$ to $72 \%$ annually) than CPNPs, who decreased as active prescribers between 2006 and 2010 (Figure 2).

Nurses prescribed $1.2 \%$ of all items on ePACT during the time period rising from $1.1 \%(8,760,634 / 773,090,199)$ in $2006-7$ to $1.5 \%(13,573,943 / 907,152,654)$ in $2009-10$.

\section{Trends in the types of medicines and medicinal products} prescribed by nurses

The volume of prescriptions written by nurses varied between the different BNF [50] categories of medicines and medicinal products. In 109 of 771 BNF [50] categories there were no nurse prescriptions at all. The greatest volume of items prescribed by nurses is given in Table 2 (with data for more categories provided in Additional file 1: Table S1) demonstrating both the different types of medicine categories those with different qualifications can prescribe from and percentage of the total prescribed in the period in general practice.

The BNF [50] categories where nurses prescribed more than $10 \%$ of the total items prescribed in primary care over 5 years were all among wound dressings, devices and incontinence or stoma appliances (Table 3 with further data presented in Additional file 2: Table S2). In the 32 BNF [50] categories of wound dressings, incontinence and stoma appliances associated devices nurses prescribed more than $20 \%$ of the total items prescribed in these categories over the time period.

The BNF [50] categories which had the greatest increase in nurse prescribing over the study period

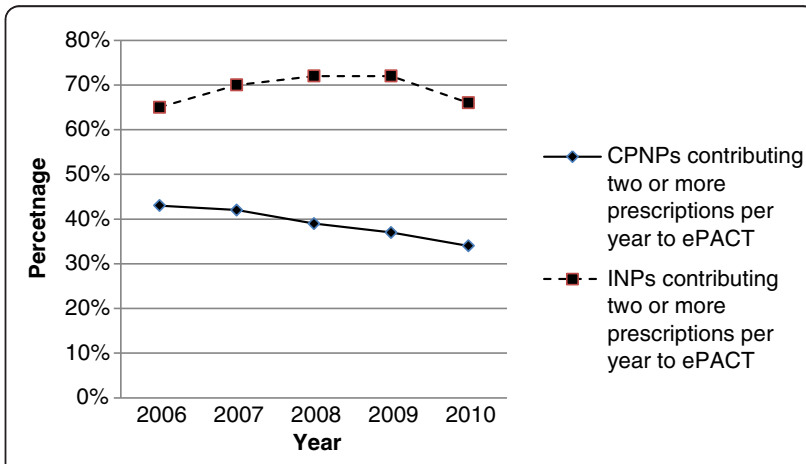

Figure 2 Trends in percentage of primary care nurses, registered on ePACT, prescribing 2006-2010. 
Table 2 The five BNF categories from which nurses prescribed the most items 2006-2010 (descending order)

\begin{tabular}{|c|c|c|c|c|c|c|}
\hline \multicolumn{4}{|c|}{ INPs } & \multicolumn{3}{|l|}{ CPNPs } \\
\hline & Category & $\begin{array}{l}\text { Number of } \\
\text { items }\end{array}$ & $\begin{array}{l}\% \text { of all items prescribed in } \\
\text { primary care }\end{array}$ & Category & $\begin{array}{l}\text { Number of } \\
\text { items }\end{array}$ & $\begin{array}{l}\% \text { of all items prescribed in } \\
\text { primary care }\end{array}$ \\
\hline 1 & Penicillins & $3,773,977$ & $4.05 \%$ & Dressings & $7,700,458$ & $16.32 \%$ \\
\hline 2 & Dressings & $2,303,643$ & $4.88 \%$ & Devices & $1,314,417$ & $2.68 \%$ \\
\hline 3 & $\begin{array}{l}\text { Adrenoceptor } \\
\text { Agonists }\end{array}$ & $1,642,286$ & $1.61 \%$ & Emollients & 909,523 & $1.43 \%$ \\
\hline 3 & $\begin{array}{l}\text { Non-Opioid } \\
\text { Analgesics }\end{array}$ & $1,593,641$ & $0.88 \%$ & $\begin{array}{l}\text { Incontinence } \\
\text { appliances }\end{array}$ & 313,654 & $4.24 \%$ \\
\hline 5 & Devices & $1,410,479$ & $2.88 \%$ & Stoma appliances & 305,767 & $2.28 \%$ \\
\hline
\end{tabular}

(difference in percentage of items between the first and last 6 months of the 5-year period) included, apart from wound dressings and incontinence and stoma devices, were preparations for de-sloughing wounds (16\%), emergency contraception (8\%), penicillins (6\%), preparations for vaginal and vulval infections (5\%), and preparations for cuts and abrasions (5\%) e.g. cetrimide cream, flexible collodion.

\section{Primary care context and prescribing}

In 2010 general practice employed independent nurse prescribers (INPs) contributed up to $2 \%$ of all items prescribed. In two PCT areas general practice-employed INPs prescribed more than $3 \%$ of items, and one PCT area had over $5 \%$. However, there were no prescriptions recorded from INPs employed in general practices in $8 \%$ (13 of 154) of PCTs. Independent nurse prescribers employed by PCTs contributed under $0.5 \%$ of items prescribed in most PCTs. Nineteen PCTs had employed INPs who contributed higher percentages of items. Only in 3 PCTs was this over $1 \%(1.3 \%, 1.3 \%$ and $2.1 \%)$.

The level of nurse prescribing in different PCT areas was not obviously related to the general practitioner variables or patient age distribution, except for an association between the number of GPs per capita and nurse prescribing. Figure 3 presents a smoothed (lowess) regression line relating the GPs per capita to the percentage of items prescribed by nurses, on a logarithmic scale. This suggests that the PCT areas with the fewest GPs per capita have nurses who prescribe approximately double the percentage of items than the PCT areas with the most GPs (Spearman's rho $=-0.16$ ). However, the trend was only apparent at the extremes and there was a great deal of unexplained variation between PCT areas, so it cannot be regarded as more than tentative evidence for increased nurse prescribing where there are fewer general practitioners per capita. Although there was a weak positive correlation between higher PCT deprivation and more GPs per capita (Spearman's rho $=0.22$ ), we also found that in more deprived PCT areas there were higher proportions of items prescribed by nurses (Figure 4; Spearman's rho $=0.19)$.

\section{Discussion}

This study has used NHS prescription administrative databases to examine trends in prescribing practices of 30,753 (2006) rising to 36,281 (2010) primary care nurses in England. To our knowledge this study presents data on the prescribing practices of the largest number of primary care nurses to date.

We found that NHS employers authorised greater numbers of primary care nurses to prescribe over the time period. The percentage actually prescribing as

Table 3 The five BNF categories where nurses make the greatest contribution to prescribing in primary care $2006-2010$ (descending order)

\begin{tabular}{|c|c|c|c|c|c|c|}
\hline \multicolumn{4}{|c|}{ INPs } & \multicolumn{3}{|l|}{ CPNPs } \\
\hline & Category & $\begin{array}{l}\text { Number of } \\
\text { items }\end{array}$ & $\begin{array}{l}\% \text { of all items prescribed in } \\
\text { primary care }\end{array}$ & Category & $\begin{array}{l}\text { Number of } \\
\text { items }\end{array}$ & $\begin{array}{l}\% \text { of all items prescribed in } \\
\text { primary care }\end{array}$ \\
\hline 1 & $\begin{array}{l}\text { Emergency } \\
\text { Contraception }\end{array}$ & 123,082 & $9.06 \%$ & $\begin{array}{l}\text { Gel And Colloid } \\
\text { Dressings }\end{array}$ & 22891 & $26.98 \%$ \\
\hline 2 & $\begin{array}{l}\text { Drugs for } \\
\text { threadworms }\end{array}$ & 50,673 & $5.15 \%$ & Dressings & $7,700,458$ & $16.32 \%$ \\
\hline 3 & Medicated stockings & 6,807 & $5.12 \%$ & Alcohols and saline & 56,191 & $16.02 \%$ \\
\hline 4 & Oils & 43,950 & $5.00 \%$ & Medicated stockings & 19,314 & $14.52 \%$ \\
\hline 5 & Dressings & $2,303,643$ & $4.88 \%$ & $\begin{array}{l}\text { Incontinence } \\
\text { appliances }\end{array}$ & 313,654 & $4.24 \%$ \\
\hline
\end{tabular}




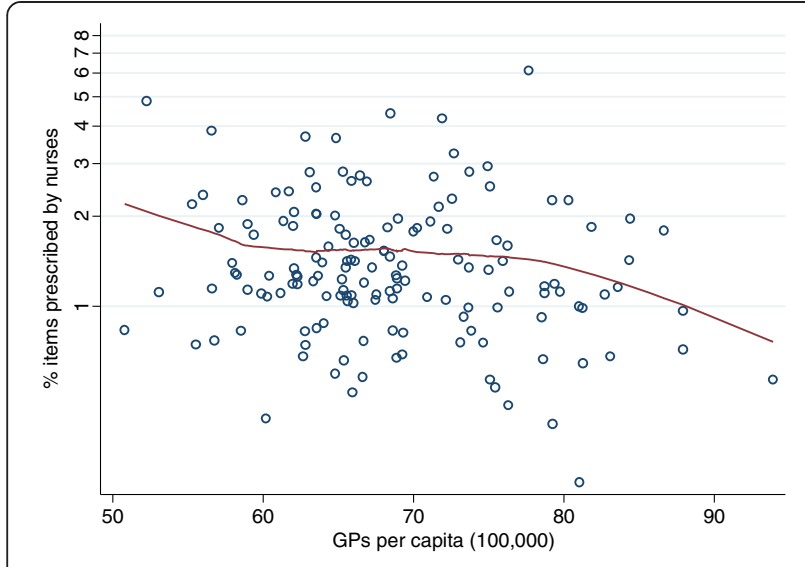

Figure 3 Percentage of items prescribed by nurses in relation to the number of GPs per population capita.

recorded by the prescription administrative system remained static over time (43\%). We have objectively quantified the percentages of nurses that are using their independent nurse prescriber (INP) qualification and demonstrated a decline in use of community nurse prescribing (CNP) qualifications, not reported previously. We found higher percentages of nurses in primary care not using their prescribing qualifications than reported by generic surveys, including primary care, in the USA $[32,33]$ and the UK [12,29] but lower than Australia [34] where prescribing rights have been more recently introduced. The finding of regional variation, with areas with no prescribing by practice employed nurses, has been noted before [58] but the evidence here suggests this feature has not changed over time.

These findings suggest that this innovation has yet to be fully adopted as usual or normal practice for primary care nurses with prescribing qualifications [11]. Some UK studies have suggested nurses' lack of employer support $[30,59]$ and there is a need for change champions in

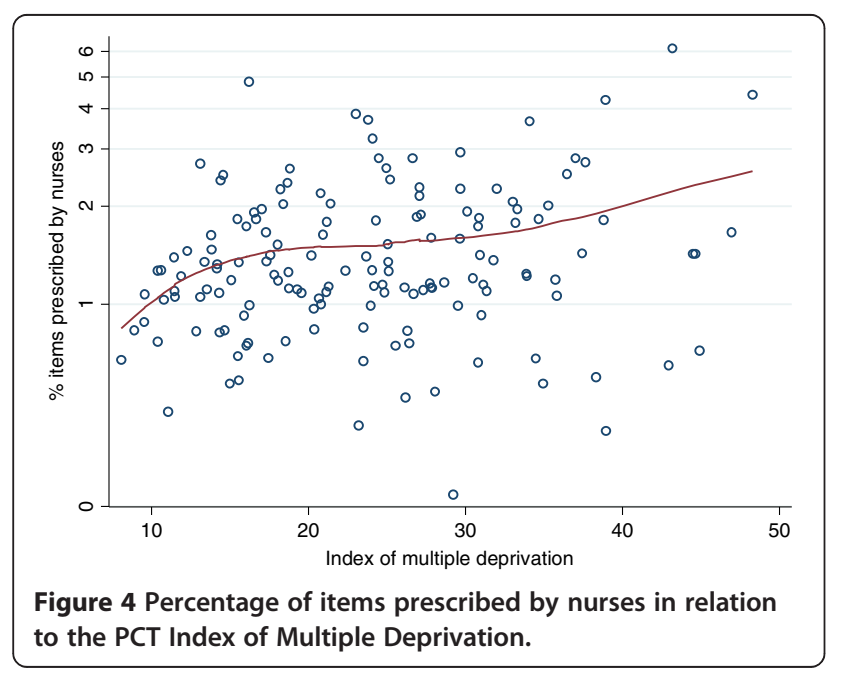

local health care systems [60], however these were nurses who had employer support as evidenced by the employer registering them as prescribers with the ePACT database. It raises questions as to why such numbers of nurses have gained the prescribing qualification for it then not to be used in practice. One hypothesis, derived from the literature [30,59] and requiring testing, is that nurses who have access to a clinical mentor or supervisor are more likely to prescribe than those who no or little access. A second hypothesis that requires further investigation is that the ambivalence to this role is more wide spread amongst primary care nurses than previously reported and they are choosing not to prescribe and as such acting as street-level bureaucrats' [61] i.e. as front line staff making policy through their implementation decisions. Primary care nurses acting as street-level bureaucrats in the face of policy implementation has been noted before in the UK [62] and other countries [63].

While the number of nurses and the volume of prescribing by nurses increased over the five year period, prescribing in primary care remains an activity mainly undertaken by doctors in England. This has been noted previously [64] and in other countries where nurses prescribe in primary care [36]. We found that the largest volume of items prescribed by nurses in primary care (both INPs and CNPs) were those items used in common nursing care activities practice i.e. wound dressings, incontinence and stoma devices. Beyond these, the medicine categories where there had been the greatest increase in both volume and percentage of prescribing compared to GPs, were those that could be bracketed as health promotion e.g. contraception, smoking cessation [65]. While practice nurses have become involved in the chronic disease management processes for primary care patients $[66,67]$ it is not evident from this study that as a group they undertake significant prescribing with these patients. Surveys of practice nurses in the UK over the last two decades show that health promotion and family planning activities are ranked as the most frequent $[68,69]$. One hypothesis, that requires further investigation, is that nurse prescribing is most acceptable to both nurses and others when it improves their efficiency in delivering primarily nursing interventions, treatments or health promotion within their scope of practice. Such investigation could include the prescribing practices of nurses with specific responsibilities for patients with long term conditions such as community matrons in the English setting [70].

We found tentative evidence that there may be higher rates of nurse prescribing in areas with lower ratios of GPs to patient populations (Spearman's rho $=-0.16$ ) and higher levels of deprivation (Spearman's rho $=0.19$ ). We suggest this requires further investigation over time and 
in the face of predicted shortages of GPs in deprived and rural areas, where the UK and other countries have difficulty in attracting and retaining family doctors $[71,72]$.

Our findings of the first five years following the introduction of independent nurse prescribing, involving all classes of medicines, suggests that while the English policy objectives were for increased flexibility professional roles [40,41], this has only been at the margins of medical practice. However, it may have significantly improved access and efficiency in health care for some groups of patients and released medical time. Prescribing by nurses in primary care for specific patient groups has the potential to release general practitioner time. Economic modelling, from one UK study, for patients with infections and those with hypertension, suggested the involvement of independent nurse prescribers was less expensive compared to a GP only prescribing model [12]. Further investigation is required over longer periods and specifically examining questions of efficiency, improved access and cost effectiveness for different patient populations.

The study has a number of limitations. As an analysis of a data set established for financial reimbursement, it cannot investigate at the patient or prescriber level. Hence, we were not able to address other aspects of nurse prescribing activities such as ceasing medications. Nor is it able to address questions such as clinical safety or health economics. The data are limited to five years of prescriptions in NHS England and other mechanisms which circumvent the ePACT database may be in place such as patient group directions [73] (known elsewhere by terms such as 'standing orders' [74]) with bulk purchase e.g. vaccines, masking a greater level of nurse activity in prescribing. However, despite these limitations this study provides empirical data and insights not available elsewhere as to the types of prescribing undertaken by primary care nurses, over time and from a national perspective. As such it offers some valuable information to nurses and policy makers both in the UK and elsewhere and in addition sets a research agenda for future study.

\section{Conclusions}

The percentage of prescriptions written by nurses in primary care in England is very small in comparison to general practitioners and there has been little change in that over five years. The adoption of any innovation in health care systems is influenced by a range of contextual and individual factors. Our findings suggest that nurse prescribing has been most frequently used in situations where it is seen to have relative advantage by all stakeholders, in particular when it supports efficiency in nursing practice, most commonly of wound and incontinence management but also the health promotion activities of nurses in general practice. It is in these areas that there appears to be flexibility in the prescribing role between nurses and general practitioners.

\section{Additional files}

Additional file 1: Table S1. The 20 British National Formulary categories from which nurses prescribed the most items, 2006-2010 (descending order), by prescribing qualification.

Additional file 2: Table S2. The 20 British National Formulary categories where nurses made the greatest contribution to prescribing in primary care, 2006-2010 (descending order), by prescribing qualification.

\section{Competing interests}

The authors declare that they have no competing interests.

\section{Authors' contributions}

VMD conceived, designed, undertook interpretation and wrote the first draft of the paper. RG designed, undertook statistical analysis, interpretation and made intellectual contribution in the drafting of the paper. $\mathrm{RH}$ designed, undertook interpretation and made intellectual contribution in the drafting of the paper. All authors read and approved the final manuscript.

\section{Acknowledgements}

The authors received no external funding to undertake the study. The authors acknowledge their gratitude to the freedom of information team at the NHS Business Authority, who responded promptly and comprehensively to our requests for data.

Received: 2 September 2013 Accepted: 31 January 2014

Published: 6 February 2014

\section{References}

1. World Health Organisation: The World Medicines Situation Report. Geneva: World Health Organization; 2011. http://www.who.int/medicines/areas/ policy/world_medicines_situation/en/.

2. International Council for Nursing: Trends and issues in nursing: implementing nurse prescribing. Geneva: International Council for Nursing; 2011.

3. Jallow MT: Essential drugs in the Gambia. World Health Forum. 1993, 14:136-9.

4. Logie D, Harding R: An evaluation of a morphine public health programme for cancer and AIDS pain relief in Sub-Saharan Africa. BMC Public Health 2005, 5:82. doi:10.1186/1471-2458-5-82.

5. Miles K, Seitio O, McGilvray M: Nurse prescribing in low-resource settings: professional considerations. International Nursing Review 2006, 53:290-296.

6. Bullogh B: Professionalization of Nurse Practitioners. Annual Review of Nursing Research 1995, 13:239-265.

7. Niger: Decree No. $88-129 / P C M S / M S P / A S$ prescribing procedures for the implementation of Ordinance No. 88-19 of 7 April 1988 authorizing the practice of contraception, 7 April 1988. Annual Review of Population Law 1988, 15:18.

8. Hemachidha C, Rosenfield AG: National health services and family planning: Thailand, a case study. American Journal of Public Health 1975, 65:864-871. doi:10.2105/AJPH.65.8.864

9. Department of Health: Report of the Advisory Group on Nurse Prescribing (Crown Report). London: Her Majesty's Stationary Office; 1989.

10. Wilhelmsson S, Ek AC, Akerlind I: Opinions about district nurses prescribing. Scandinavian Journal of Caring Science 2001, 15:326-30.

11. Greenhalgh T, Robert G, Macfarlane F, Bate P, Kyriakidou O: Diffusion of innovations in service organizations: systematic review and recommendations. Milbank Quarterly 2004, 82:581-629.

12. Latter S, Blenkinsopp A, Smith A, Chapman S, Tinelli M, Gerard K, Little P, Celino N, Granby T, Nicholls P, Dorer G: Evaluation of nurse and pharmacist independent prescribing. Southampton: University of Southampton \& University of Keele; 2011 [http://eprints.soton.ac.uk/184777/3/ENPIPfullreport. pdf]

13. Naughton C, Drennan J, Hyde A, Allen D, O'Boyle K, Felle P, Butler M: An evaluation of the appropriateness and safety of nurse and midwife 
prescribing in Ireland. Journal of Advanced Nursing 2013, 69:1478-88. doi:10.1111/jan.12004. Epub 2012 Sep 192012.

14. Abbott A: The system of professions: An essay on the division of expert labor. Chicago: University of Chicago; 1988.

15. Kroezen M, Dijk L, Groenewegen P, Francke A: Nurse prescribing of medicines in Western Europe and Anglo-Saxon countries: a systematic review of the literature. BMC Health Service Research 2011, 11:127. doi:10.1186/1472-6963-11-127.

16. Kroezen M, Francke AL, Groenewegen PP, Van Dijk L: Nurse prescribing of medicines in Western European and Anglo-Saxon countries: a survey on forces, conditions and jurisdictional control. Int J Nurs Stud. 2012, 49:1002-12. doi:10.1016/j.jinurstu.2012.02.002.

17. Horton R: Nurse-prescribing in the UK: right but also wrong. The Lancet 2002, 359:1875-6.

18. Moller P, Begg E: Independent nurse prescribing in New Zealand. New Zealand Medical Journal 2005, 118:U1724.

19. Desroches J: Should prescribing authority be shared with non-physicians? No. Canadian Family Physician 2009, 55:1177-8.

20. Australian Medical Association: AMA Takes Strong Stance on non-medical prescribing. 30/03/2012. Australian Medical Association; 2012. [https://ama. com.au/media/ama-takes-strong-stance-non-medical-prescribing]

21. American Journal of Nursing: Editorial: APNs Win Prescribing Role in States Aiming at Reform. American Journal of Nursing 1994, 5:78-80.

22. Plonczynski D, Oldenburg N, Buck M: The past, present and future of nurse prescribing in the United States. Nurse Prescribing 2003, 1:170-174.

23. Hughes F, Lockyer $\mathrm{H}$ : Evidence and engagement in the introduction of nurse prescribing in New Zealand. Nurse Prescribing 2004, 2:131-136.

24. Jones M: Case Report. Nurse prescribing: a case study in policy influence. Journal of Nursing Management 2004, 12:266-72.

25. Kaplan L, Brown MA: The transition of nurse practitioners to changes in prescriptive authority. Journal of Nursing Scholarship 2007, 39:184-90.

26. Ryan-Wolley B, McHugh G, Lucker K: Prescribing by specialist nurses in cancer and palliative care: results of a national survey. Palliative Medicine 2007, 21:272-277.

27. Lockwood EB, Fealy GM: Nurse prescribing as an aspect of future role expansion: the views of Irish clinical nurse specialists. Journal of Nursing Management 2008, 16:813-20.

28. Snowden A, Martin CR: Mental health nurse prescribing: a difficult pill to swallow? Journal of Psychiatric and Mental Health Nursing 2010, 17:543-553. doi:10.1111/j.1365- 2850.2010.01561.x.

29. Courtenay $M$, Carey N: Nurse Independent Prescribing and Nurse Supplementary Prescribing: Findings from a national questionnaire survey. Journal of Advanced Nursing 2008, 61:291-299. doi:10.1111/j.1365-2648.2007.04512.x.

30. Kelly A, Neale J, Rollings R: Barriers to extended nurse prescribing among practice nurses. Community Practitioner 2010, 83:21-24.

31. Wells J, Bergin M, Gooney M, Jones A: Views on nurse prescribing: a survey of community mental health nurses in the Republic of Ireland. Journal of Psychiatric and Mental Health Nursing 2009, 2009(16):10-7.

32. Goolsby MJ: AANP National Nurse Practitioner Sample Survey, Part II: nurse practitioner prescribing. Journal of the American Academy of Nurse Practitioners 2005, 17:506-11.

33. Goolsby MJ: 2009-2010 AANP national nurse practitioner sample survey: An overview. Journal of the American Academy of Nurse Practitioners 2011, 23:266-268. doi:10.1111/j.1745-7599.2011.00611.x.

34. Dunn SV, Cashin A, Buckley T, Newman C: Nurse practitioner prescribing practice in Australia. J Am Acad Nurse Pract. 2010, 22:150-5. doi:10.1111/j.1745-7599.2009.00484.x.

35. Luker K, Wright K, Austin L: Evaluation of Nurse Prescribing: Final Report Liverpool: University of Liverpool and the University of York; 1997.

36. Cipher DJ, Hooker RS, Guerra P: Prescribing trends by nurse practitioners and physician assistants in the United States. Journal of the American Academy of Nurse Practitioners 2006, 18:291-6.

37. Murphy AL, Martin-Misener R, Cooke C, Sketris I: Administrative claims data analysis of nurse practitioner prescribing for older adults. Journal of Advanced Nursing 2009, 65:2077-87.

38. Jagwe J, Merriman A: Uganda: delivering analgesia in rural Africa: opioid availability and nurse prescribing. Journal of Pain \& Symptom Management 2007, 33:547-51.

39. Shell RC: Antidepressant prescribing practices of nurse practitioners. Nurse Practitioner 2001, 26:42-44.
40. Department of Health: The NHS Improvement Plan: putting People at the Heart of Public Services. Cm 6268. London: The Stationery Office; 2004.

41. Department of Health: Our health, our care, our say: a new direction for community services. Cm 6737. London: The Stationery Office; 2006.

42. Great Britain. Medicinal Products: Prescription by Nurses etc Act (C.28). London: Her Majesty's Stationary Office; 1992.

43. Britain G: Medicinal Products: Prescription by Nurses, etc Act 1992: (Commencement No 1) Order. London: Her Majesty's Stationary Office; 1996.

44. National Health Service Executive: Nurse Prescribing; Implementing the Scheme across England. Health Service Circular 1998/233. Leeds: National Health Service Executive; 1998.

45. Britain G: The Health and Social Care Act 2001, Section 63. London: The Stationary Office; 2001.

46. Great Britain: The Medicines and Human Use (Prescribing) (Miscellaneous Amendments) Order 2006 and associated medicines regulations. London: The Stationary Office; 2006

47. Department of Health: Extending independent nurse prescribing within the NHS in England: A guide for implementation. Edition 1. London: The Stationery Office; 2002

48. DH/Medicines, Pharmacy \& Industry/Clinical \& Cost Effectiveness : Improving Patients' Access to Medicines: A Guide to Implementing Nurse and Pharmacist Independent Prescribing within the NHS in England. London: Department of Health; 2006.

49. Nursing \& Midwifery Council: Standards for proficiency in nurse and midwife prescribers. London: Nursing \& Midwifery Council; 2006.

50. British Medical Association and the Royal Pharmaceutical Society, British Medical Association and the Royal Pharmaceutical Society. British National Formulary, British Medical Association and the Royal Pharmaceutical Society: British National Formulary. London: British Medical Association and the Royal Pharmaceutical Society; 2012. [www.bnf.org/bnf/index.htm]

51. Bhanbhro S, Drennan VM, Grant R, Harris R: Assessing the contribution of prescribing in primary care by nurses and professionals allied to medicine: a systematic review of literature. BMC Health Service Research 2011, 11:330. doi:10.1186/1472-6963-11-330.

52. Department of Health: The NHS Constitution. 2012. [https://www.gov.uk/ government/publications/the-nhs-constitution-for-england]

53. Health \& Social Care Information Centre. NHS Staff General Practice - detailed results - England, 1999-2009. 2010. [http://www.hscic.gov.uk/catalogue/ PUB01977]

54. Britain G: Freedom of Information Act 2000. London: The Stationary Office; 2000.

55. Noble M, McLennan D, Wilkinson K, Whitworth A, Barnes H, Dibben C: The English Indices of Deprivation 2007. London: Communities and Local Government; 2008.

56. NHS Yorkshire and Humber Public Health Observatory: Index of Multiple Deprivation 2007: average PCT scores. 2011. [www.yhpho.org.uk/resource/ item.aspx?RID=10003]

57. StataCorp: Stata statistical software: release 11. Texas, USA.X: College Station; 2009.

58. Davis K, Drennan V: Evaluating nurse prescribing behaviour using constipation as a case study. International Journal of Nursing Practice 2007, 4:243-53.

59. Downer F, Shepherd C: District nurses prescribing as nurse independent prescribers. British Journal of Community Nursing 2010, 15:348-352.

60. Courtenay M, Carey N, Stenner K: Non-medical prescribing leads views on their role and the implementation of non-medical prescribing from a multi-organisational perspective. BMC Health Services Research 2011, 11:142. doi:10.1186/1472-6963-11-142.

61. Lipsky M: Street-level bureaucracy. Updated Edition. New York: Russell Sage Foundation; 2010.

62. Walker L, Gilson L: 'We are bitter but we are satisfied': nurses as street-level bureaucrats in South Africa. Social Science \& Medicine 2004, 59:1251-1261

63. Bergen A, While A: 'Implementation deficit'and 'street-level bureaucracy': policy, practice and change in the development of community nursing issues. Health \& Social Care in the Community 2005, 13:1-10.

64. Bissell P, Cooper R, Guillaume L, Anderson C, Avery A, Hutchinson A, James V, Lymn J, Marsden E, Murphy E, Ratcliffe J, Ward P, Woolsey I: An Evaluation of Supplementary Prescribing in Nursing and Pharmacy for the Department of Health. University of Sheffield; 2008 [http://eprints.whiterose.ac.uk/76239/1/ Supplementary_prescribing.pdf] 
65. De Jong J, Visser MR, Wieringa-de Waard M: Exploring differences in patient mix in a cohort of GP trainees and their trainers. BMJ open 2011, 1:e000318. doi:10.1136/bmjopen-2011-000318.

66. McGregor W, Jabareen H, O'Donnell CA, Mercer SW, Watt GC: Impact of the 2004 GMS contract on practice nurses: a qualitative study. British Journal of General Practice 2008, 58:711-9.

67. Griffiths P, Murrells T, Maben J, Jones S, Ashworth M: Nurse staffing and quality of care in UK general practice: cross-sectional study using routinely collected data. British Journal of General Practice 2010, 60:e36-e48. doi:10.3399/bjgp10X482086.

68. Atkin K, Hirst M, Lunt N, Parker G: The role and self-perceived training needs of nurses employed in general practice: observations from a national census of practice nurses in England and Wales. Journal of Advanced Nursing 1994, 20:46-52. doi:10.1046/j.1365-2648.1994.20010046.x.

69. Crossman S: The Working in Partnership Programme General Practice Nurse Snapshot Survey. London: The Working in Partnership Programme; 2008 [http://www.wipp.org.uk/uploads/GPN/Final\%20SNAPshot\%20Survey\% 20Report\%20SC.pdf]

70. Drennan V, Goodman C, Manthorpe J, Davies S, Scott C, Gage H, lliffe S: Establishing new nursing roles: a case study of the English community matron initiative. Journal of Clinical Nursing 2011, 20(19-20):2948-2957.

71. Dussault G, Franceschini MC: Not enough there, too many here: understanding geographical imbalances in the distribution of the health workforce. Human Resources for Health 2006, 4:12. doi:10.1186/1478-4491-4-12

72. Goddard M, Gravelle H, Hole A, Marini G: Where did all the GPs go? Increasing supply and geographical equity in England and Scotland. Journal of Health Service Research \& Policy 2010, 15:28-35.

73. Department of Health: Patient Group Directions [England only]. Health Service Circular HSC 2000/026. London: Department of Health; 2000

74. Zimmerman R, Albert SM, Nowalk MP, Yonas MA, Ahmed F: Use of standing orders for adult influenza vaccination: a national survey of primary care physicians. American Journal of Preventive Medicine 2011, 40:144-148

doi:10.1186/1472-6963-14-54

Cite this article as: Drennan et al:: Trends over time in prescribing by English primary care nurses: a secondary analysis of a national prescription database. BMC Health Services Research 2014 14:54.

\section{Submit your next manuscript to BioMed Central and take full advantage of:}

- Convenient online submission

- Thorough peer review

- No space constraints or color figure charges

- Immediate publication on acceptance

- Inclusion in PubMed, CAS, Scopus and Google Scholar

- Research which is freely available for redistribution 